\title{
Selection of Belt Conveyors Drive Units Number by Technical - Economical Analysis
}

\author{
Zoran Despodov ${ }^{1, a}$, Stojance Mijalkovski ${ }^{1, b}$, Vanco Adziski ${ }^{1, c}$ \\ and Zoran Panov ${ }^{1, d}$ \\ ${ }^{1}$ University Goce Delcev, Faculty of Natural and Technical Sciences, Goce Delcev 89, 2000 Stip, \\ Republic of Macedonia \\ azoran.despodov@ugd.edu.mk, bstojance.mijalkovski@ugd.edu.mk, 'adziski.v@gmail.com, \\ dzoran.panov@ugd.edu.mk
}

Keywords: pulley, drive, tension, belt conveyor, cost

\begin{abstract}
In this paper is presented a methodology for selection of belt conveyor drive units number by technical - economical analysis of their parameters. Belt Conveyors with follow drive arrangement will be considered: one, two, three and four drive units. In the technical - economical analysis are including: Tension forces, Power of belt conveyor, Costs for belt, Costs for power and reducers, Total cost for belt conveyor system.
\end{abstract}

\section{Introduction}

Power station is one of the most expensive elements of the belt conveyor which carries transporting material from the place of loading to unloading place. The problem of choosing the number of drive units in belt conveyor installation is current problem that designers must find an appropriate solution.

Large dimensions of power station on single pulley drive pose a serious problem in underground mines, not only because of the limited space, but also because there an overload of the belt conveyor [1].

The application of multi pulley drives in underground mines brings the following advantages:

- possibility of using of interchangeable driving units and of motors with maximum permissible power considering a control system,

- situation of a discharge point of the extracted material at a greater distance from drives,

- reduction of the excavation in the vicinity of drives (the drives are situated on one side of a conveyor),

- reduction of the foundation work,

- concentration of the accompanying facilities and equipment such as: travelling cranes for assembly purposes, electric power substations, belt cleaning devices, brakes, mechanical back-stop, equipment tor monitoring and controlling the conveyor operation, water coolers etc. in one place.

In more recent time for long conveyors there is an increasing use for the so-called distributed drive power [2] or drives installed along the route of the belt conveyor. This paper aims to propose a methodology for selecting the number of power units in belt conveyor located at the head of the transporter on the basis of technical and economic analysis.

\section{Tension forces in various power systems of the belt conveyor}

Tension forces in the belt have a decisive role in selecting the number of power units in belt conveyor and strength of the belt. On the other hand, the effective tightening of the belt depends on the total resistance of movement of the belt or the type and capacity of the transported material, and from the mass of the belt and route conditions. 
To analyze the underlying influences and power relations in the belt and pulleys for achieving the plant, we will start from single pulley drive, and then we will extend the analysis to the multiple pulley drives in belt conveyors.

Single pulley drive. Scheme of single pulley drive is shown in Fig.1.

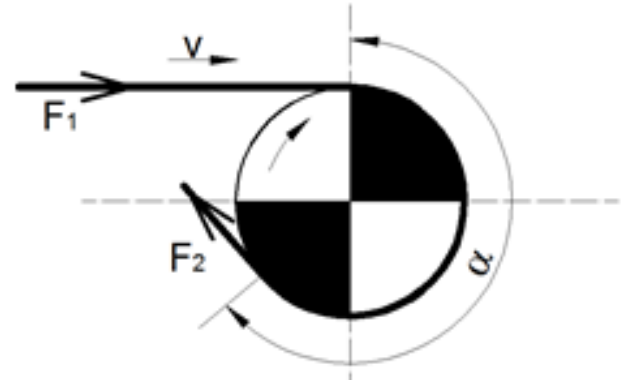

Fig. 1 Single pulley drive [3]

Parameters in Fig. 1 are:

$\alpha=$ angle of wrap on pulley (in radians),

$\mu=$ friction of belt on pulley,

$\mathrm{F}_{1}=$ tension in "tight" belt,

$\mathrm{F}_{2}=$ tension in "slack" belt,

$\mathrm{e}=$ base of Napier an logs.

Belt slap is given by the form from Eytelwein and will occur when:

$$
\frac{F_{1}}{F_{2}}=e^{\mu \alpha}
$$

The difference in tension between the tight side and the slack side of the belt is described as the effective tension. Thus:

$$
F_{e}=F_{1}-F_{2}
$$

The effective tension is related to power required at the drive pulley and the belt speed. Thus the power required:

$$
P_{e}=F_{e} \cdot v
$$

Where $v$ is the belt speed, $\left(\frac{m}{s}\right)$.

From this we can conclude that the power transmitted may be increased if:

1) if coefficient of friction is increased, $\mu$

2) if angle of wrap is increased, $\alpha$

3) if effective tension in belt is increased, $\mathrm{F}_{\mathrm{e}}$.

We are particularly interested in those factors that enable the reduction of tension on belt conveyors, and that is the wrap angle $\alpha$, and coefficient of friction $\mu$. If in equation (2) tension in "tight" belt $F_{1}$ is express through force $F_{2}$, the effective tension will be:

$$
F_{e}=F_{1}-F_{2}=F_{2} \cdot e^{\mu \alpha}-F_{2}=F_{2}\left(e^{\mu \alpha}-1\right)
$$

From here: 
$F_{2}=\frac{F_{e}}{e^{\mu \alpha}-1}$ or $F_{2}=K \cdot F_{e}$ where: $K=\frac{1}{e^{\mu \alpha}-1}$ is called the drive factor

For example, if we assume a belt wrap $\alpha=230^{\circ}$ and $\mu=0.25$, then:

$$
\begin{aligned}
& K=\frac{1}{e^{0.25 \cdot 4}-1}=0.58 \\
& F_{2}=0.58 \cdot F_{e} \text { and } F_{1}=F_{e}+F_{2}=1.58 \cdot F_{e}
\end{aligned}
$$

Selection of quality belt conveyor for a particular plant is based on the maximum force of tension [5]. From the previous equations it is clear that the ability of the pulley to move the belt will increase if the angle of wrap is increased around the pulley or coefficient of friction is increased.

In practise single pulley drive are usually limited to an arc of contact of about $230^{\circ}$ (exceptionally $240^{\circ}$ ) when using a snub pulley behind the drive pulley. Improved coefficient of friction may be obtained by suitably lagging the drive pulley surface.

Tandem drive. Here belt tension estimated to be high, the angle of wrap is increased by adopting tandem drives. Wrap angle of the belt is increased with arrangement of tandem drive, Fig. 2. Both of tandem pulleys are driven. The tandem drive with arc of contact from $300^{\circ}$ to $480^{\circ}$ or more can operate with one or two motors. The location of such drive is usually determined by the physical requirements of the plant and structural constraints.

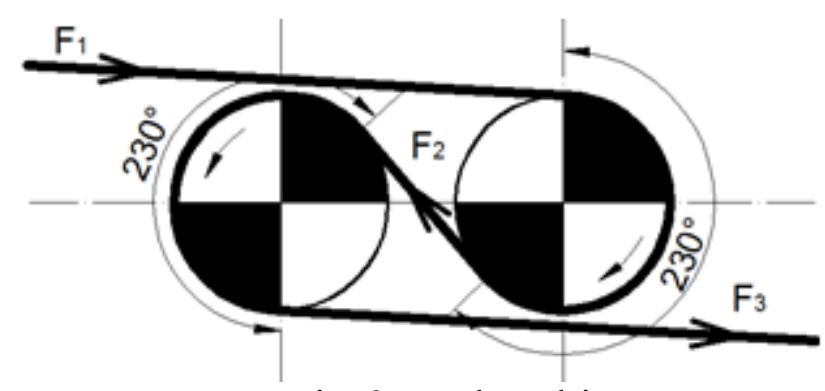

Fig. 2 Tandem drive

Dual pulley drives. The next level of development of drive pulley systems in belt conveyors is creating a dual pulley drives in which the driving pulley are separately driven and they are not mechanically connected Fig. 3. Each drive pulley is driven by two electric motors.

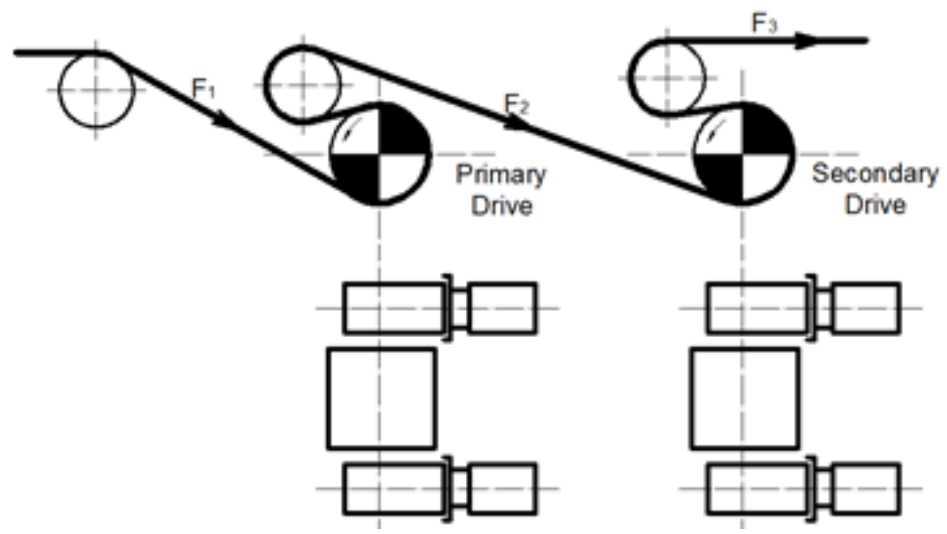

Fig. 3 Dual pulley drives

In the following text is described the certain characteristic strengths of the tension forces for this type of plant. The effective tension on the primary pulley is: 


$$
F_{e p}=F_{1}-F_{2}
$$

Here we have : $\quad \frac{F_{1}}{F_{2}}=e^{\mu p \cdot \alpha p} \quad$ from which follows: $F_{1}=F_{2} \cdot e^{\mu p \cdot \alpha p}$

$$
F_{e p}=F_{2} \cdot e^{\mu p \cdot \alpha p}-F_{2}=F_{2} \cdot\left(e^{\mu p \cdot \alpha p}-1\right)
$$

Effective tension on the secondary pulley is:

$$
F_{e s}=F_{2}-F_{3}
$$

But:

$$
\frac{F_{2}}{F_{3}}=e^{\mu s \cdot \alpha s} \quad \text { and } \quad F_{3}=\frac{F_{2}}{e^{\mu s \cdot \alpha s}}
$$

Thus:

$$
F_{e s}=F_{2}-\frac{F_{2}}{e^{\mu s \cdot \alpha s}}=F_{2} \cdot\left(\frac{e^{\mu s \cdot \alpha s}-1}{e^{\mu s \cdot \alpha s}}\right)
$$

For conditions where $\mu_{\mathrm{p}}=\mu_{\mathrm{s}}=0.25$ and $\alpha_{\mathrm{p}}=\alpha_{\mathrm{s}}=230^{\circ}$, the proportion from the above formula is 0.73 to 0.27 or $73 \%$ of the total belt load is transmitted through the primary drive and $27 \%$ of the total load through the secondary pulley. This proportion is variable and depends on the arc of contact on each pulley and the values of the coefficient of friction between the belt and each pulley.

The previously adopted values for the angle of wrap and the coefficient of friction we can calculate the slack and the tight side belt tensions:

$$
\begin{aligned}
& \frac{F_{1}}{F_{2}}=e^{\mu p \cdot \alpha p}=2.727 \text { and } \\
& \frac{F_{2}}{F_{3}}=e^{\mu s \cdot \alpha s}=2.727 \text { from which: } \\
& F_{1}=\left(2.727^{2}\right) \cdot F_{3} .
\end{aligned}
$$

Then the total effective tension in the belt is:

$$
\begin{aligned}
& F_{e}=F_{1}-F_{3} \\
& F_{e}=F_{3} \cdot\left[\left(2.727^{2}\right)-1\right] \text { or } \\
& F_{3}=\frac{F_{e}}{\left(2.727^{2}\right)-1}=0.155 \cdot F_{e} \\
& F_{1}=F_{e}+F_{3}=1.155 \cdot F_{e} .
\end{aligned}
$$

Commonly used in practice is desirable to use power units of equal size in terms of standardization of reduction of gears and motors. Commonly applied arrangements of this kind of drive systems include:

1) one or two power units joined to each drive pulley to give an equal load distribution

2) three power units, two being joined to the primary pulley and one of the secondary pulley giving a load distribution of $2: 1$. 
In the first case: $F_{1}-F_{2}=0.5 \cdot F_{e}$ and $F_{2}-F_{3}=0.5 \cdot F_{e}$ and for $\mu_{\mathrm{p}}=\mu_{\mathrm{s}}=0.25$ and $\alpha_{\mathrm{p}}=\alpha_{\mathrm{s}}=230^{\circ}$ we get that:

$$
F_{2}=2.727 \cdot F_{e} ; F_{3}=0.289 \cdot F_{e} ; F_{1}=F_{e}+F_{3}=1.289 \cdot F_{e} .
$$

In the second case: $F_{1}-F_{2}=0.667 \cdot F_{e}$ and $F_{2}-F_{3}=0.333 \cdot F_{e} ; \frac{F_{2}}{F_{3}}=e^{\mu s \cdot a s}=2.727$ from which follows:

$$
F_{2}=2.727 \cdot F_{3} \text { or } F_{3}=0.193 \cdot F_{e} \text { and maximum tension: } F_{1}=F_{e}+F_{3}=1.193 \cdot F_{e}
$$

\section{Technical - economical analysis for selection of the number of drive units in belt conveyors}

In order to select the optimal number of drive units for belt conveyor that will work in specific working conditions it is necessary first to make technical and economical analysis. One methodology for the technical and economic analysis of belt conveyor is shown in Fig. 4.

Function of aim as can be seen from Fig. 4, is selection of elements of the belt conveyor to be such that the total cost for it to be minimal, [4].

Based on this methodology is developed a computer program in Microsoft Excel. Belt conveyor is processed with the following operating conditions: $\mathrm{L}=600 \mathrm{~m}, \mathrm{H}=63 \mathrm{~m}, \mathrm{Q}_{\mathrm{h}}=580 \mathrm{~m}^{3} / \mathrm{h}, \gamma_{\mathrm{r}}=2 \mathrm{t} / \mathrm{m}^{3}$.

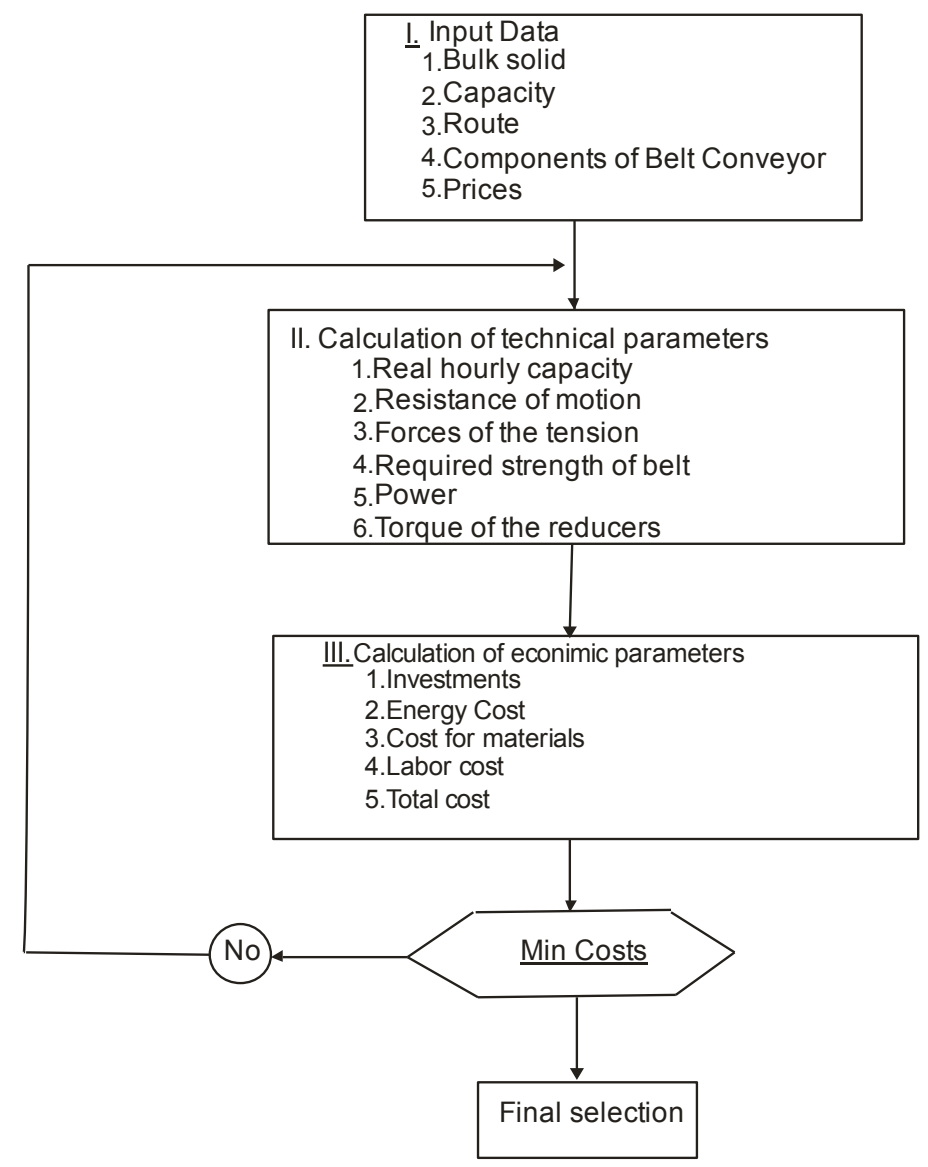

Fig. 4 Methodology for technical-economical analysis on belt conveyor

The choice for the number of drive units is made on the basis of available four alternative cases:

1) Single pulley drive with one motor

2) Tandem drive with two motors

3) Dual pulley drives (one pulley with two motors and one pulley with one motor)

4) Dual tandem pulley drives ( $2 \mathrm{x}$ one pulley with two motors). 
With the developed computer program in Microsoft Excel is calculated the technical parameters for the different drive systems and they are shown in Table 1. The total resistance on the belt are calculated according to DIN 22101 standard, [6]. The technical parameters of the considered drive systems as well as the operating condition of the given belt conveyor are values obtained from a theoretical example.

Table 1 Technical parameters of the considered drive systems

\begin{tabular}{|c|c|c|c|c|c|}
\hline Parameter & Units & $1 \mathrm{EM}$ & 2EM(1xtandem) & $3 \mathrm{EM}$ & 4EM $(2 x$ tandem $)$ \\
\hline Width of belt & {$[\mathrm{mm}]$} & 1200 & 1200 & 1200 & 1200 \\
\hline Speed of belt & {$[\mathrm{m} / \mathrm{s}]$} & 2.12 & 2.12 & 2.12 & 2.12 \\
\hline Breaking load of belt & {$[\mathrm{kN} / \mathrm{m}]$} & 3150 & 2500 & 2500 & 2000 \\
\hline $\begin{array}{l}\text { Angle of wrap on } \\
\text { primary pulley }\end{array}$ & {$\left[{ }^{\circ}\right]$} & 230 & 460 & 230 & 460 \\
\hline $\begin{array}{l}\text { Angle of wrap on } \\
\text { secondary pulley }\end{array}$ & {$\left[{ }^{0}\right]$} & & & 230 & 460 \\
\hline Coefficient of friction & & 0.25 & 0.25 & 0.25 & 0.25 \\
\hline $\begin{array}{l}\text { Force of maximal } \\
\text { tension, } \mathrm{F}_{\max }\end{array}$ & {$[\mathrm{kN}]$} & 367.045 & 267.802 & 276.513 & 231.866 \\
\hline $\begin{array}{l}\text { Force of minimal } \\
\text { tension, } \mathrm{F}_{\min }\end{array}$ & {$[\mathrm{kN}]$} & 134.616 & 36.022 & 44.734 & 4.279 \\
\hline $\begin{array}{l}\text { Force of effective } \\
\text { tension, } \mathrm{F}_{\mathrm{e}}\end{array}$ & {$[\mathrm{kN}]$} & 232.429 & 231.780 & 231.780 & 227.587 \\
\hline $\mathrm{F}_{\max } / \mathrm{F}_{\mathrm{e}}$ & & 1.579 & 1.554 & 1.193 & 1.0188 \\
\hline $\mathrm{F}_{\min } / \mathrm{F}_{\mathrm{e}}$ & & 0.579 & 0.554 & 0.193 & 0.0188 \\
\hline Required strength of belt & {$[\mathrm{kN} / \mathrm{m}]$} & 3059 & 2232 & 2304 & 1932 \\
\hline Load distribution ratio & & & $1: 1$ & $2: 1$ & $1: 1$ \\
\hline Power of EM & {$[\mathrm{kW}]$} & $1 \times 630$ & $2 \times 315$ & $3 \times 200$ & $4 \times 160$ \\
\hline Torque of reducer & {$[\mathrm{Nm}]$} & 4121 & 2060 & 1308 & 1047 \\
\hline Number of drive pulley & & 1 & 2 & 2 & 4 \\
\hline
\end{tabular}
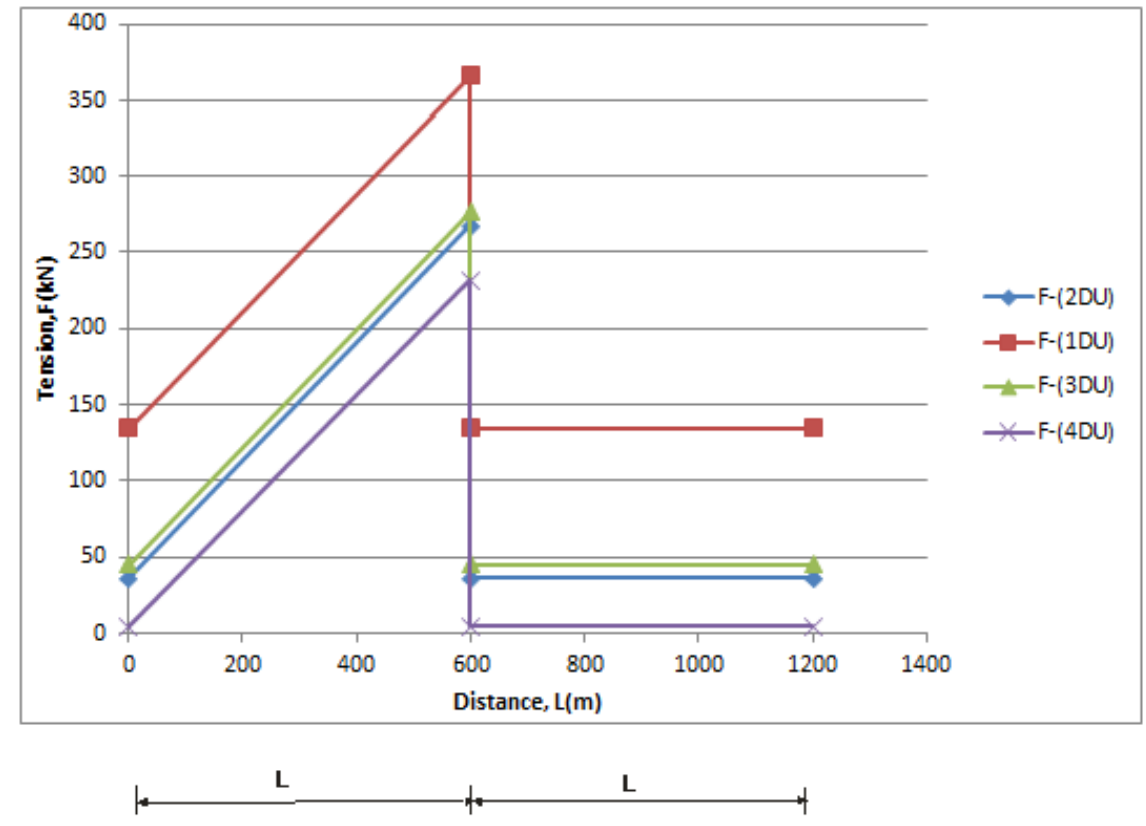

Fig. 5 Tension forces of belt 
The values of the tension forces of the belt in specific points of the transporter are shown graphically on Fig. 5. From the diagram below we can see that by increasing the number of power units and the value of wrap angle come to reducing the total tension on the belt. Based on the assumed prices of the elements of belt conveyor, with help of economical analysis is estimated the cost of the belt, cost of operation and total cost as the sum of the previous cost. The values of cost per meter of the belt conveyor are shown graphically on Fig. 6.

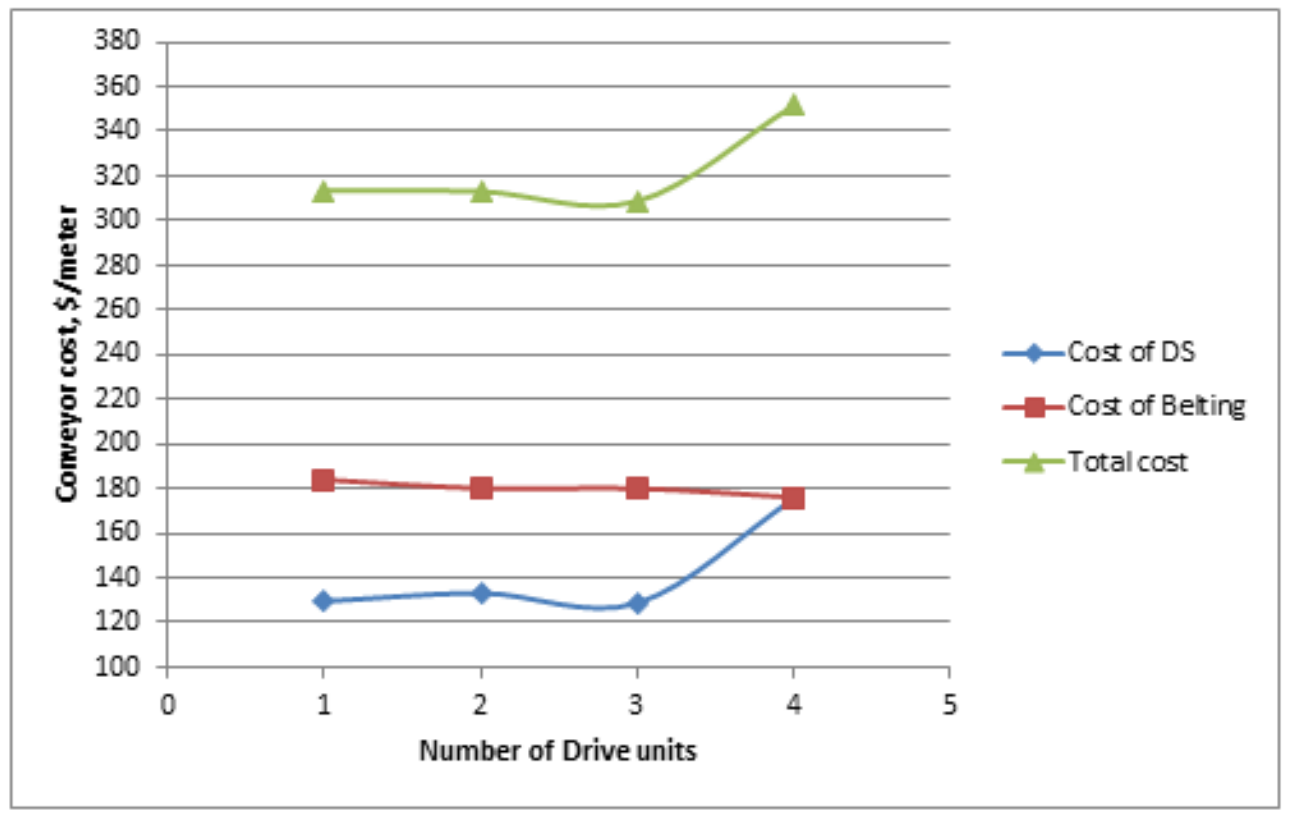

Fig. 6 Optimal number of drive units depending on the total cost

\section{Summary}

When designing the drive units on belt conveyors, except technical parameters into account should be taken also the economic parameters to perform a proper choice of the drive unit. For this particular example of belt conveyor which we analysed in this paper the optimal choice of drive unit is a system with three drive motors because the total cost is minimal.

\section{References}

[1] J. Antoniak, Inclined Belt Conveyors for Underground Mining Applications, Transport \& Logistics 1 (2001) 47-59.

[2] A. Nuttal, Design Aspects of Multiple Driven Belt Conveyors, dissertation, Delft Technical University, ISBN 978-90-5584-092-2, 2007.

[3] G. Fedorko, V. Molnár, P. Michalik, Pipe conveyors, Technical University of Košice, Košice, 2012. (original in Slovak).

[4] Z. Despodov, D. Mirakovski, Mathematical model for optimal transportation system selection in underground metal mines, Transport \& Logistics 3 (2002) 57-68.

[5] P. Bindzár, D. Malindžák, Number of conveyor belts optimization regarding to its type and logistical parameters in mining industry, Acta Montanistica Slovaca 14/4 (2008) 524-531. (original in Slovak).

[6] J. Antoniak, A. Lutinski, J. Dyduch, W. Augustowski, Manual for users of Belt Conveyor and other rubber product in production of FTT Stomil Wolbrom Limited Company, Wolbrom-Gliwice, 1995. 